\title{
Paleoparasitologia no Brasil
}

\author{
Paleoparasitology in Brazil
}

M arcelo L. C. Gonçalves 1

Adauto Araújo 1

Luiz Fernando Ferreira 1

Abstract We review the beggining of paleoparasitology and its development in Brazil. The search of parasites in ancient human remains can throw light on such questions as origin and antiquity of parasite-host relationship, general distribution of parasites through time and prehistoric human migrations. The study of parasite DN A sequences found in mummified tissues and coprolites can be an important source of information for phylogenetic and host-parasite coevolution. The nucleic acid based techniques (molecular paleoparasitology) open a new perspective to evolution at a molecular level.

Key words Paleoparasitology, Coprolites, Ancient feces, M ummies, Ancient diseases
Resumo N este artigo faz-se uma revisão sobre o início da paleoparasitologia no Brasil e seu desenvolvimento. A pesquisa de parasitos em vestígios humanos pode trazer informações sobre questões tais como a origem eantiguidade da relação parasi to-hospedei ro, distribuição de parasi tos através do tempo e migrações humanas pré-históricas. 0 estudo de seqüências deADN de parasitos encontrados em tecidos mumificados e coprólitos pode ser uma importante fonte de informação para filogenia e co-evolução parasito-hospedeiro. A análise de ácidos nucléicos de parasitos encontrados em material arqueológico ( paleoparasitologia molecular) abre novas perspectivas para estudos sobre evolução ao nível molecular.

Palavras-chave Paleoparasitologia, Coprólitos, Fezes antigas, Múmias, D oenças no passado

\footnotetext{
1 Departamento de Escola Nacional de Saúde Pública, Fundação O swaldo Cruz. Rua Leopoldo Bulhões, 1.480 térreo 21041-210 Rio de Janeiro RJ. mlcg@ig.com.br
} 


\section{Introdução}

Paleoparasitologia é o ramo da paleopatologia que estuda os parasitos em material arqueológico ou paleontológico. No início do século 20, os estudos pioneiros de Sir M arc Armand Ruffer, quando descreve ovos de Schistosoma haematobium nos rins de múmias egípcias, lançam a pedra fundamental da nova ciência. Ruffer desenvolveu técnicas de reidratação de tecidos mumificados, possibilitando preparações histológicas e conseqüentemente o diagnóstico de doenças em populações do antigo Egito. 0 intercâmbio com egiptólogos ampliou as perspectivas de estudo dos parasitos do passado (Ruffer, 1921).

A associação entre arqueólogos e parasitologistas começou a se estruturar mais tarde, com a anál ise de coprólitos (fezes mineralizadas ou preservadas pela dessecação) coletados em sítios arqueológicos e enviados aos laboratórios. Entretanto, por limitações técnicas, até a metade daquele século, descreveram-se em coprólitos rel ativamente poucos ovos e larvas de helmintos parasitos de animais e de humanos, sendo que estes últimos principalmente em corpos mumificados e no conteúdo de fossas medievais européias (Szidat, 1944; Pizzi \& Schenone, 1954; Taylor, 1955).

0 uso de solução aquosa de fosfato trissódico como reidratante, uma adaptação da técnica usada para recuperar espécimens dessecados em coleções de museu, impulsionou a paleoparasitologia a partir da década de 1960. Este método, utilizado em coprólitos preservados por dessecação, permitiu o uso de técnicas parasitológicas comumente aplicadas nos laboratórios clínicos (Callen \& Cameron, 1960; Reinhard et al., 1988). Os achados de ovos e larvas de parasitos tornaram-se mais freqüentes e começou-se a perceber as potencialidades desta nova ciência, com todas as suas implicações no estudo da evolução das relações parasito-hospedeiro e nos estudos de dispersão das espécies. A paleoparasitologia mostrou desde logo sua vocação para a interdisciplinaridade.

As primeiras pesquisas no Brasil objetivaram refutar a crença até então existente de que as doenças parasitárias não eram significantes na pré-história do Novo M undo. Os primeiros resultados desta linha de pesquisa, ovos de Trichuris trichiura e ancilostomídeos datados de épocas pré-Colombianas, foram apresentados no Congresso Brasileiro de Parasitologia, em 1979 (Ferreira et al., 1979). Na mesma ocasião cunhou-se o termo Paleoparasitologia para esta nova ciência.

\section{A técnica clássica}

Consiste no exame microscópico de um fragmento do coprólito. 0 exame é simples e pouco dispendioso. Através do aspecto morfológico do coprólito e do tipo e presença de restos alimentares, procura-se identificar sua origem zoológica.

A técnica consiste na retirada de um fragmento do coprólito. Caso o coprólito esteja preservado por dessecação, a reidratação é feita com solução aquosa de fosfato trissódico $\left(\mathrm{Na}_{3} \mathrm{PO}_{4}\right)$ a $0,5 \%$ por 72 horas (Callen $\&$ Cameron, 1960 ). Em caso de coprólito mineralizado, utiliza-se ácido clorídrico $10 \%$ até sua desagregação, conforme a técnica de Jones (1983).

A pós esta etapa, o material é concentrado pela técnica de sedimentação espontânea (Reinhard et al., 1988). 0 sedimento é então examinado através de microscopia óptica, sendo os parasitos encontrados medidos e fotografados. Através das medidas dos ovos encontrados, são usadas tabelas de ovos de parasitos e hospedeiros para comparações morfométricas, na tentativa de identificar a espécie do parasito envolvido e confirmar ou não a origem humana do coprólito (Confalonieri et al., 1988; Chame et al., 1991).

A datação do material é realizada por métodos físicos (radiocarbono ou termoluminescência) diretamente no coprólito ou na camada geológica onde foi encontrado, ou ainda por contexto cultural.

\section{Os coprólitos e a paleoepidemiologia}

A análise macro e microscópica dos coprólitos, além de parasitos, pode revelar importantes informações sobre padrões de dieta, paleoclimas e adaptações paleoecológicas (Wilke \& Hall, 1975). Os tipos de resíduos orgânicos presentes nos coprólitos, tais como pólens, fibras, grãos de amido e fragmentos ósseos, assim como avaliações do contexto arqueológico do local de encontro do coprólito, permitem inferências sobre dados culturais dos povos antigos. A prática da agricultura pode ser identificada a partir do encontro de al gumas variedades vegetais.

Estudos de patoecologia em agricultores pré-históricos mostraram que o grau de infec- 
ção parasitária do grupo era dependente de padrões sanitários, tipo de moradia e ambiente. Infecções por Enterobius vermicularis, por exemplo, mostraram padrões diversos entre povos agricultores e caçadores-coletores préhistóricos. À medida que os habitantes de determinada região passaram a se sedentarizar, usando abrigos ou grutas como moradia, ou construindo habitações, a freqüência de ovos de parasitos em coprólitos aumenta (Reinhard et al., 1987; Reinhard, 1992).

Outras inferências podem ser feitas quanto aos hábi tos al imentares e infecções parasitárias. A infecção por Diphyllobothrium pacificum, cestódeo parasito de mamíferos marinhos com ciclo evolutivo em peixes e crustáceos, foi diagnosticada em populações pré-históricas sulamericanas da costa do Pacífico, há pelo menos 4.000 anos (Patrucco et al., 1983; Ferreira et al., 1984). Os dados da paleoparasitologia mostram a persistência de hábitos alimentares por um longo período nesta região, uma vez que a infecção foi descrita na população atual, cujos hábitos alimentares, no caso o prato típico "cebiche", ainda permanecem (Baer, 1969).

\section{A paleoparasitologia e as migrações pré-históricas}

U ma importante contribuição da paleoparasitologia refere-se às migrações pré-históricas humanas e povoamento dos continentes. Já no fim do século 19 questões referentes a parasitismo e migrações pré históricas humanas despertavam o interesse de pesquisadores. Os estudos de Olímpio da Fonseca sobre parasitismo em populações indígenas contemporâneas isoladas trouxeram contribuições para as teorias de povoamento das Américas (Fonseca, 1972), introduzindo um novo marcador biológico às argumentações de ordem cultural sobre origem e vias migratórias de populações préhistóricas. A paleoparasitologia, por outro lado, a partir do encontro de ovos de parasitos em coprólitos humanos, trouxe uma contribuição importante aos estudos epidemiológicos que usam dados atuais para inferências sobre movimentos migratórios préhistóricos.

A análise da distribuição de infecções parasitárias no passado possibilita especulações quanto às migrações humanas em diferentes regiões ao longo do tempo assim como contatos interpopulacionais, uma vez que, sob a ótica evolucionista, uma determinada espécie bio- lógica não surge em mais de um ponto geográfico. Com isso, podeseconfirmar ou refutar teorias de povoamento e propor alternativas com base em achados paleoparasitológicos (H orne, 1985; N ozais, 1985; Araújo \& Ferreira, 1997).

Logo após a descoberta, o povoamento do continente americano foi objeto de especulações. Já em 1590 frei José de Acosta sugeria uma via terrestre entre a Ásia e a América do $\mathrm{N}$ orte como porta de entrada do novo mundo para os habitantes pré colombianos. Por quase 400 anos essa explicação reinou sem sobressaltos no ambiente acadêmico, sendo a origem asiática, via Estreito de Bering, dos primeiros habitantes das Américas dada como certa.

Durante o último período glacial, no final de pleistoceno, com o abaixamento de mais de 90 metros do nível dos oceanos, o continente asiático e o americano ficaram unidos por uma faixa gelada de terra, a Beríngia, possibilitando deslocamentos humanos. U tilizando rotas no norte do continente americano por entre geleiras, esses primeiros habitantes teriam povoado progressivamente as novas terras mais ao sul.

0 estudo de coprólitos humanos tem levantado dúvidas sobre o modelo clássico do povoamento pré-colombiano das Américas peIo Estreito de Bering. As teorias clássicas propostas sobre o povoamento sugerem ondas migratórias por esta região, em número e época variáveis. Entretanto, este modelo não pode justificar o encontro de ovos de ancilostomídeos e de Trichuris trichiura em coprólitos oriundos de sítios arqueológicos das Américas há pelo menos 7.200 anos (Allison et al., 1974; Ferreira et al., 1980, 1983; 1987; A raújo et al., 1981). 0 clima frio da Beríngia não permitiria a persistência deste tipo de parasitismo na população migrante, agindo como um verdadeiro filtro (M anter, 1967; Fladmark, 1979; Araújo et al., 1988; Ferreira \& Araújo, 1996). Deste modo, a transmissão de parasitos com parte de seu ciclo evolutivo obrigatoriamente no solo seria interrompida ao longo das gerações de hospedeiros humanos que se sucederam por esta via migratória (Araújo et al., 1985; A raújo \& Ferreira, 1995; Hugot et al., 1999).

Tais achados sugerem, na verdade, rotas alternativas, por mar, como uma possibilidade para as migrações humanas na América préhistórica, tornando questionável a exclusividade absoluta do Estreito de Bering como porta de entrada (Araújo \& Ferreira, 1996). Esta é uma linha cujos resultados se acumulam, criando dados consistentes para discussões sobre 
origem de populações de hospedeiros em novos territórios.

\section{Os novos horizontes: biologia molecular e ancient DNA}

0 uso de técnicas de biologia molecular, especialmente a reação em cadeia da polimerase $(P C R)$, expandiu em muito o horizonte da paleoparasitologia. A técnica baseia-se na amplificação in vitro de regiões específicas de DNA. Com o auxílio de primers complementares a seqüências específicas localizadas em uma das extremidades do segmento a ser amplificado, obtêm-se milhões de cópias do segmento de DNA amplificado.

A utilização de novas técnicas de biologia molecular em material antigo deve ser precedida de um estudo controlado em material recente experimentalmente dessecado (Bastos et al., 1996). Ainda que apresente dificuldades metodológicas em sua aplicação em material antigo, sobretudo referentes à inibição da reação por elementos do solo presentes no material arqueológico, à contaminação ambiental por DN A recente ou ainda pela dificuldade de obtenção de primers confiáveis e específicos (Hänni et al., 1991), o uso da PCR inaugura uma nova era no diagnóstico paleoparasitológico. M uito mais sensível do que o exame direto, o uso da técnica da PCR e de suas variantes tem permitido o diagnóstico de infecções parasitárias em material antigo até então inacessíveis à microscopia óptica.

Diversas infecções parasitárias têm sido diagnosticadas em populações pré-históricas através da técnica da PCR. Borrelia burgdorferi em carrapatos de coleção de museu (Persing et al., 1990), M ycobacterium tuberculosis em corpos humanos mumificados (Spigelman \& Lemma, 1993; Salo et al., 1994; Arriaza et al., 1995) são alguns exemplos do uso da biologia molecular no diagnóstico parasitológico em material antigo.

O diagnóstico de infecção chagásica em múmias sul-americanas datadas em até 4.000 anos através da técnica de PCR, com a amplificação de minicírculos do cinetoplasto do Trypanosoma cruzi, confirmou a antiguidade da infecção humana por este parasito (Guhl et al., 1997, 1999; Ferreira et al., 2000). Entretanto, a hipótese de que tenha sido conseqüente à domiciliação do Triatoma infestans em regiões andinas e posteriormente se distribuído pelo continente poderá ser confrontada com novos dados paleoparasitológicos. A possibilidade do encontro de DNA deT. cruzi em esqueletos humanos de sítios arqueológicos, como os da Serra da Capivara, Piauí, onde se localizam alguns dos mais antigos sítios arqueológicos das Américas, descortina uma nova hipótese, a de que a doença de Chagas seja tão antiga no continente quanto os humanos. Os vestígios arqueológi cos mostraram a presença de animais reservatórios e vetores em áreas ocupadas pelos primeiros habitantes da região.

\section{A paleoparasitologia molecular ea filogenia}

A possibilidade de se trabal har com genomas de parasitos numa perspectiva evolutiva abre um novo campo para estudos filogenéticos. 0 seqüenciamento de ácido nucléico de parasitos (Chilton \& Gasser, 1999; Le et al., 2000; Bellocq et al., 2001) e a recuperação de material genético de helmintos parasitos humanos em material antigo (Loreille et al., 2001) permitem antever um campo fértil para estudos sobre origem e evolução das doenças parasitárias e seus agentes etiológicos. A comparação de seqüências de ácido nucléico de parasitos separados por intervalos de tempo de al guns milhares de anos poderá trazer respostas sobre variações na virulência de patógenos que, conjuntamente com os estudos de patoecologia de parasitos, possibilitará maior entendimento sobre emergência e reemergência de doenças infecciosas (Araújo \& Ferreira, 2000). Sobre este mesmo caminho, a paleoparasitologia sem dúvida contribuirá com novas teorias sobre as relações parasito-hospedeiro, voltadas sobretudo para coevolução e modelos de virulência, e o próprio conceito de parasitismo.

A paleoparasitologia tornou-se um caminho para estudos sobre a origem de hospedeiros, suas rotas de migração no passado e distribuição atual, fornecendo dados para outras ciências relacionadas às origens da espécie humana. 


\section{Referências bibliográficas}

Allison M J, Pezzia A, H asegawa, I \& Gerszten E 1974. A case of hookworm infection in a pre-Columbian American. American Journal of Physical Anthropology 41:103-106.

Araújo A \& Ferreira LF 1995. Oxiuríase e migrações préhistóricas. História, Ciências, Saúde - M anguinhos 1: 99-109.

Araújo A \& Ferreira LF 1996. Paleoparasitology and the peopling of the Americas. Fundhamentos 1:106-114.

Araújo A \& Ferreira LF 1997. H omens e parasitos: a contribuição da paleoparasitologia para a questão da origem do homem na América. Revista da U niversidade de São Paulo 34:58-70.

Araújo A \& Ferreira LF 2000. Paleoparasitology and the antiquity of human host-parasite relationships. M emórias do Instituto O swaldo Cruz 95:89-93.

Araújo A, Ferreira LF\& Confalonieri U 1981. A contribution to the study of helminth findings in archaeological material in Brazil. Revista Brasileira de Biologia 41:873-881.

Araújo A, Ferreira LF, Confalonieri U \& Chame M 1988. Hookworms and the peopling of America. Cadernos de Saúde Pública 2:226-233.

Araújo A, Ferreira LF, Confalonieri U, N uñez L \& Ribeiro BM 1985. The finding of Enterobius vermicularis eggs in pre-Columbian human coprolites. M emórias do Instituto Oswaldo Cruz 80:141-143.

Arriaza BT, Salo W, Aufderheide AC \& H olcomb TA 1995. Pre-Columbian tuberculosis in northern Chile: molecular and skeletal evidence. American Journal of Physical Anthropology 98:37-45.

Baer JG 1969. Diphyllobothrium pacificum, a tapeworm from sea lions endemic in along the coastal area of Peru. Journal Fisheries Research Board of Canada 26:717-723.

Bastos OM , Araújo A, Ferreira LF, Santoro A, Wincker $P$ $\&$ M orel LC 1996. Experimental paleoparasitology: identification of Trypanosoma cruzi DNA in dessicated mouses tissues. Paleopathology N ewsletter 94:5-8.

Bellocq JG, Ferté H, Depaquit J, Justine JL, Tillier A \& Desset M CD 2001. Phylogeny of the Trichostrongylina (Nematoda) inferred from $28 \mathrm{~S}$ rDN A sequences. M olecular Phylogenetics and Evolution 19:430-442.

Callen EO \& Cameron TWM 1960. A prehistoric diet as revealed in coprolites. N ew Scientist 8:35-40.

Chame M , Ferreira LF, Araújo A \& Confalonieri U 1991. Experimental paleoparasitology: an approach to the diagnosis of animal coprolites. Paleopathology $\mathrm{N}$ ewsletter 76:7-9.

Chilton N B \& Gasser RB 1999. Sequence differences in the internal transcribed spacers of DNA among four species of hookworm (Ancylostomatoidea: AncyIostoma). International Journal for Parasitology 29: 1.971-1.977.

Confalonieri U, Ferreira LF, Araújo A \& Ribeiro BM 1988. The use of a statistical test for the identification of helminth eggs in coprolites. Paleopathology Newsletter 62:7-8.

Ferreira LF \& Araújo A 1996. On hookworm in the Americas and trans-pacific contact. Parasitology Today $12: 454$.

Ferreira LF, Araújo A \& Confalonieri UEC 1979. Subsídios para a paleoparasitologia do Brasil. I. Parasitos encontrados em coprólitos no município de U naí, M G. Resumos de IV Congresso Brasileiro de Parasitologia, Campinas, p. 56.

Ferreira LF, Araújo A \& Confalonieri UEC 1980. Finding of helminth eggs in human coprolites from Unaí, M G. Transactions of the Royal Society of Tropical $M$ edicine and $H$ ygiene 74:798-800.

Ferreira LF, Araújo A \& Confalonieri UEC 1983. The finding of helminth eggs in a Brazilian mummy. Transactions of the Royal Society of Tropical M edicine and $H$ ygiene 77 : 65-67.

Ferreira LF, Araújo A, Confalonieri UEC, Chame M \& Ribeiro BM 1987. Encontro de ovos de ancilostomídeos em coprólitos humanos datados de $7230 \pm 80$ anos, Piauí, Brasil. Anais da Academia Brasileira de Ciências 59:280-281.

Ferreira LF, Araújo, A, Confalonieri UEC \& Nuñez L 1984. The finding of eggs of Diphyllobothrium in human coprolites (4,100-1,950 B.C.) from Northern Chile. M emórias do Instituto O swaldo Cruz 79:175180.

Ferreira LF, Britto C, Cardoso A, Fernandes O, Reinhard $K \&$ Araújo A 2000. Paleoparasitology of Chagas disease revealed by infected tissues of Chilean mummies. Acta Tropica 75:79-84.

Fladmark KR 1979. Routes: Alternate migration corridors for early man in North America. American Antiquity 44:55-69.

Fonseca O 1972. Parasitismo e migrações humanas préhistóricas. M auro Familiar Editor, Rio de Janeiro.

Guhl F et al. 1999. I solation of Trypanosoma cruzi DNA in 4000-year-old mummified human tissue from Northern Chile. American Journal of Physical Anthropology 108:401-407.

Guhl F, Jaramillo C, Yockteng R, Vallejo GA \& Arroyo FC 1997. Trypanosoma cruzi DNA in human mummies. Lancet 349:1.370.

H änni C, Laudet V \& Stehelin D 1991. Paléonthologie et biologie moléculaire: la rencontre de deux mondes. Biofutur 98:55-58.

H orne PD 1985. A review of the evidence of human endoparasitism in the pre-columbian New World through the study of coprolites. Journal of Archaeological Sciences 12:299-310.

Hugot JP, Reinhard KJ, Gardner SL \& M orand S 1999. Human enterobiasis in evolution: origin, specificity and transmission. Parasite 6:201-208.

Jones AKG 1983. A coprolite from 6-8 pavement pp. 225229. In Environment and living conditions at two Anglo-Scadinavian sites. University of York, York.

Le TH, Blair D \& M cmanus DP 2000. Mitochondrial genomes of human helminths and their use as markers in population genetics and phylogeny. Acta Tropica 77:243-246.

Loreille O, Roumat E, Verneau O, Bouchet F\& Hänni C 2001. Ancient DNA from Ascaris: extration amplification and sequences from eggs collected in coprolites. International Journal of Parasitology 31:1.1011.106.

M anter HW 1967. Some aspects of the geographical distribution of parasites. Journal of Parasitology 53:1-9.

N ozais JP 1985. H ypothèses sur I'origine de certains parasites du continent latino-amèricain. Bulletin de la 
Société de Pathologie Exotique 78: 401-412.

Patrucco R, Tello R \& Bonavia D 1983. Parasitological studies of coprolites of prehispanic peruvian populations. Current Anthropology 24:393-394.

Persing DH, Telford SR, Rys PN, Dodge DE, White SE \& Spielman A 1990. Detection of Borrelia burgdoferi DNA in museum specimens of I xodes dammini ticks. Science 249:1.420-1.423.

Pizzi T \& Schenone H 1954. Hallazgo de huevos de Trichuris trichiura en contenido intestinal de un cuerpo arqueológico incaico. Boletín Chileno de Parasitologia 9:73-75.

Reinhard KJ 1992. The impact of diet and parasitism on anemia in the prehistoric West, pp. 219-258. In P. Stuart-M cAdam \& S. Kent (org.). Diet, demography and disease: changing perspectives of anemia. Aldine deGryeter, Nova York.

Reinhard KJ, Confalonieri U, Ferreira LF, Herrmann B \& Araújo A 1988. Recovery of parasite remains from coprolites and latrines: aspects of paleoparasitological technique. Homo 37:217-239.

Reinhard KJ, Hevly RH \& Anderson GA 1987. Helminth remains from prehistoric Indian coprolites from the Colorado Plateau. Journal of Parasitology 70: 630-639.
Ruffer M A 1921. Studies in paleopathology of Egypt. R M oodie, Ed.-University of Chicago Press, N ova YorkChicago.

Salo WL, Aufderheide AC, BuikstraJ \& Holcomb T 1994. Identification of M ycobacterium tuberculosis DNA in a pre-columbian peruvian mummy. Proceedings of the $N$ ational A cademy of Sciences 91:2.091-2.094.

Spigelman J \& Lemma E 1993. The use of polymerase chain reaction to detect $M$ ycobacterium tuberculosis in ancient skeletons. International Journal of O steoarchaeology 3:137-143.

Szidat L 1944. Uber die Erhaltungsfähigkeit von $\mathrm{H}$ elmintheneierm in Vor-und frühgeschchtlichen M oorleichen. Zeitschrift für Parasitenkunde 13:265274.

Taylor EL 1955. Parasitic helminths in mediaeval remains. V eterinary Record 67:216-218.

Wilke PJ \& Hall HJ 1975. Analysis of ancient feces: a discussion and annoted bibliography. University of California, Archaeological Reserch Facility, Department of Anthropology, Berkeley. 